\title{
MPRA
}

Munich Personal RePEc Archive

\section{Neither Here nor There: Regionally \\ Targeted Social Policy or Socially Targeted Regional Policy? The First Four Years of Lula's Administration}

Azzoni, Carlos Roberto and Guilhoto, J. J. M. and Haddad, E. A and Hewings, G. J. D. and Laes, M. A. and Moreira, G.

University of São Paulo

2011

Online at https://mpra.ub.uni-muenchen.de/37959/

MPRA Paper No. 37959, posted 09 Apr 2012 18:47 UTC 


\title{
Neither Here nor There: Regionally Targeted Social Policy or Socially Targeted Regional Policy? The First Four Years of Lula's Administration
}

\author{
Azzoni, C. R., Guilhoto, J. J. M., Haddad, E. A., Hewings, G. J. D., Laes, M. A., and Moreira G. \\ Universidade de São Paulo, Brazil
}

\section{Introduction}

The aim of regional policy is the attainment of a more efficient and/or equitable interregional distribution of economic activity (Temple, 1994). As demonstrated elsewhere (Haddad, 1999), Brazil has undergone, in the last twenty years or so, deep structural changes, responsible for the setback in the process of polarization reversal in the economy. After 1988, with the new Constitution, the central government was hampered by a profound loss in its revenues to the state and municipal governments. Nevertheless, the fiscal crisis reached all levels of government, decreasing their financial capability for carrying out new investment ventures. The lack of investment in economic infrastructure increased the average cost of production; producers were facing increasing costs due to the inefficient mechanisms of trade and transportation, which lagged technologically.

The regional de-concentration trend verified in the period from the 1960s to the early 1980s was heavily induced by an active government intervention, manifested in actions such as direct investments in regional development projects and tax incentives in the less developed regions of the country. However, with the fiscal crisis generalized to all levels of government, little room for new public ventures became available.

The agreed agenda for the country includes the competitive integration of the country in the global trade network, with the domestic concern of sustainable stabilization and social cohesion. This implies the attraction of foreign investments and a responsible (balanced) budget policy for all levels of government, reinforced by the promulgation of the "Lei de 
Responsabilidade Fiscal', in 2000. The latter precludes regional policies based on heavy redistributional expenditures, as was the case in the 1970s. Foreign investors search for better financial returns, and, therefore, are not concerned with regional equity; location is defined on a purely economic basis.

The results presented in Haddad (1999) suggest that the interplay of market forces in the Brazilian economy favors the more developed region of the country. In other words, the trickling-down effects generated by market forces are still very unlikely to overtake the polarization effects from the Center-South. If regional equity is part of the country's development agenda, an active regional policy by the central government is still needed, in order to reduce regional economic disparities, and specifically to address the problems of the North and Northeast, traditionally backward areas reliant on low technology activities. The improvement of the economic infrastructure in those regions, as well as the establishment of enduring competitive advantages, through a consistent human capital policy, are necessary to attenuate the adverse regional effects of the development strategy pursued by the public authorities.

Nowadays, the regional policy carried out by the central government consists of isolated subsidies and industrial incentives to growth centers, in addition to constitutional transfers to less developed regions and rural areas. In the context of the fiscal adjustment process of the 1990s, the role of the central government in stimulating directly productive activities and enhancing the social overhead capital in the lagging regions is being neglected. In the conception of the Real Plan, there was no explicit concern about the formulation of a regional development policy for the country. The Real Plan was conceived as a global stabilization plan, which would include economic reforms (privatization, concessions and deregulation) and institutional reforms (tax system, social security and administrative), without proposing any strategy for medium and long-run development. However, with the benefits from the stabilization and the reforms, a new cycle of private investments emerged. These investments tended to concentrate in the South and Southeast regions, which provided a full range of non-traditional (e.g. technical skills and urban agglomeration) and traditional (e.g. friction of distance - 
Mercosul) locational factors to attract the incoming capital. The lack of investments by the central government, allied to the spurt in private investments, has led regional governments to engage in strong competition for private capital through fiscal mechanisms.

Regarding the less developed regions of the North and Northeast, regional development necessarily demands direct government intervention. Their economic structure should evolve to higher level of specialization in those activities where the regions present dynamic competitive advantage in order to define their role in the process of interregional and international integration. In the Northeast, for instance, different studies identified the regional competitive advantage in the productive transformation of the existing economic structure, based on the restructuring and modernization of specialized industrial complexes (e.g. the petrochemical complex in Bahia, and the mining complex in Maranhão); the modernization of the agricultural sector and the agriculturally-based industries; and the expansion of tourism and related activities. This strategy will need the active participation of public authorities through the adoption of regionally differentiated fiscal incentives, when necessary, and more important, through the provision of modern economic infrastructure and the formation and development of human resources in the region, emphasizing poverty alleviation and universal primary and secondary education (see Araújo, 1995, and Albuquerque and Gomes, 1996). An increasing emphasis on "economic" rather than "financial" incentives throughout Brazil should give rise to a new form of regional incentive based explicitly on building up dynamic comparative advantages rather than granting fiscal handouts. ${ }^{1}$

Finally, the government has to identify priorities for investments in infrastructure. In this instance, the government will face conflicting choices in the allocation of the scarce resources. On the one hand, it is important to create and modernize the existing economic infrastructure in the lagging regions to facilitate the operation of the forces for the centrifugal spread of economic expansion in the more developed regions, and also to consolidate their regional competitiveness through the establishment of an effective stock

\footnotetext{
${ }^{1}$ See Amann et al. (2006)
} 
of social overhead capital. On the other hand, demands for economic infrastructure are also perceived in the Southern part of the country, in the context of the increasing exposure to international markets. Increased trade involving the more complex economic spaces in the Center-South and foreign partners will face significant transportation costs, and unless the transportation sector can be adjusted, the country will not face high gains in competitiveness both in the internal and external markets. In this regard, attempts to deepen the regional roots of inward productive investments should focus on the building up of quality infrastructure and the facilitation of enhanced integration with regional, extra-regional and international markets.

In this context, we can argue that nothing much has been done in the first four years of Lula's administration. In terms of proper regional policy, central government relied only on constitutional intergovernmental transfers through regional funds ${ }^{2}-$ FNE, FNO, FCO - and rural pensions.

However, the central government has been engaged in an effort to design and implement social compensatory policies with a strong spatial dimension. The pro-poor "Bolsa Familia Program" is a program that provides direct income transfers to poor (with per capita income between BRL 60,01 and BRL 120,00) and extreme poor households (with per capita income below BRL 60,00). Given the geographical distribution of poor households in the country (Table 1), targeting benefits to the poor reflects an implicit concern with regional disparities in the country. Even though it cannot be considered an explicit strategy of geographic targeting to reduce poverty, it may achieve the goal of classical regional policies - namely, the reduction of regional disparities - through direct income transfers to poor households, which happen to be concentrated in poorer regions. However, this remains to be tested.

\footnotetext{
${ }^{2}$ Almeida et al. (2006) have investigated the resources allocations of the Northeast (FNE), North (FNO) and Center-West (FCO) Constitutional Financing Fund loans by municipalities, and have found out that the loans have not been directed to the poorest states or to the poorest municipalities.
} 
Table 1. Households Eligible for Benefits from "Bolsa Família", 2000

\begin{tabular}{l|cc}
\hline \multicolumn{1}{c|}{ Region } & Number of Poor Households & $\%$ \\
\hline North & $1,574,094$ & 0.0917 \\
Northeast & $7,140,519$ & 0.4158 \\
South & $2,006,596$ & 0.1169 \\
Southeast & $5,342,975$ & 0.3111 \\
Mid-West & $1,107,909$ & 0.0645 \\
Total & $17,172,093$ & 1.0000 \\
\hline
\end{tabular}

Source: Demographic Census, 2000

Thus, the goal of this paper is to assess the regional impacts of the Bolsa Familia Program from a perspective of a socially targeted regional policy. After this brief introduction, we proceed, in section 2, with an analysis of the outcomes of the 2006 presidential elections, looking at Lula's performance in the first round, by municipality. We estimate different models to check what variables were determinant for his victory over the other candidates. It can be anticipated that direct income transfers through the Bolsa Familia Program can be considered one of the most robust explanatory variables for determining a better electoral performance of the Labor Party's candidate. With that result in mind, the Bolsa Familia Program is evaluated through a regional policy perspective. Section 3 describes the methodology to be used in section 4 , where the results are presented and discussed. Final remarks follow in section 5, putting the results into a broader perspective of the policy initiatives to be considered in Lula's second mandate.

\section{Voters' Evaluation: What do the ballots tell us?}

In this section we evaluate the main determinants of Lula voting in the first round of the 2006 presidential elections. We begin the analysis with the choropleth map of the election data. Figure 1 shows the data for the percentage of Lula's voting in the first round of the presidential elections in 2006 , by municipality. The spatial pattern of the votes is illustrated in this map, with the darkest shade corresponding to the highest rate range. The suggestion of spatial clustering of similar values that follows from the visual inspection of this map needs to be confirmed by formal tests. 


\section{Figure 1. Lula Voting (\% of Lula Voting in Relation to Total Voting)}

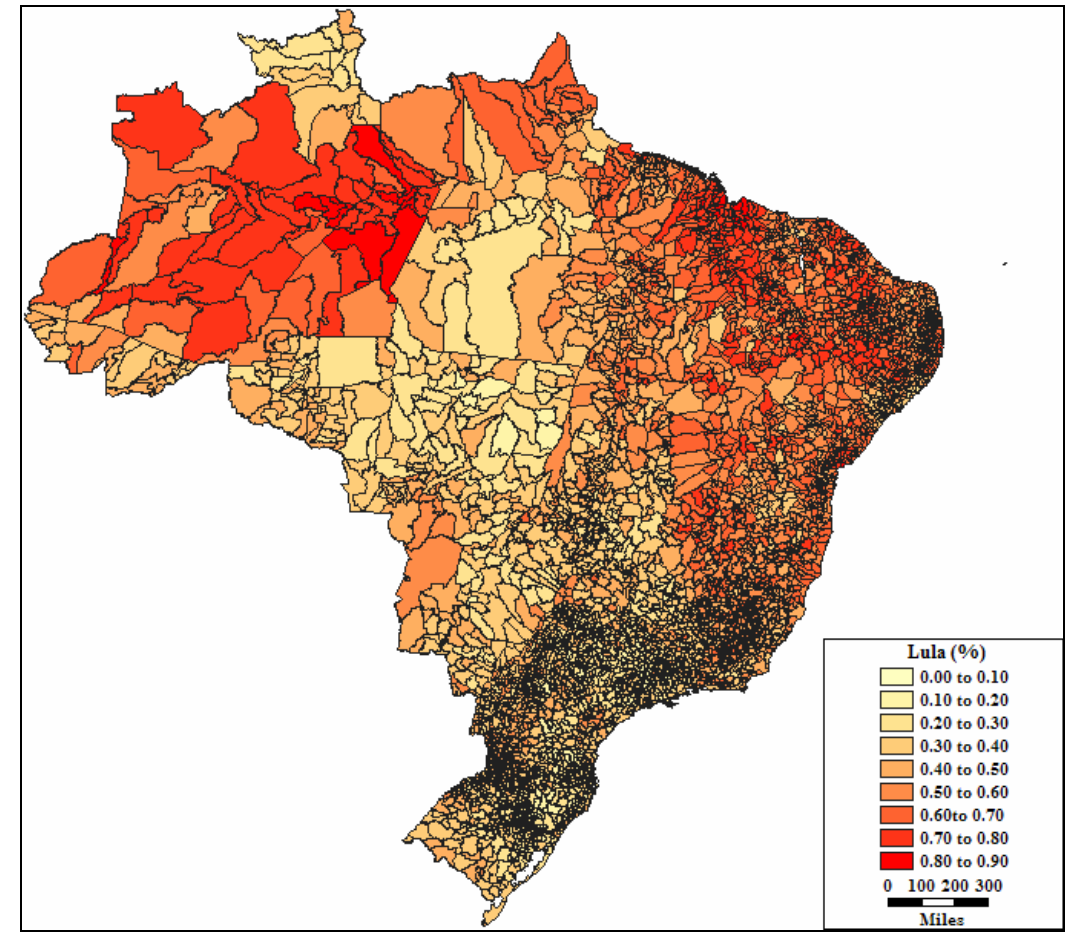

Source: TSE

The first step in a study of ESDA is to test this hypothesis: are the spatial data randomly distributed? To do that, it is necessary to use global autocorrelation statistics. The spatial correlation coefficient Moran's I was used. The underlying hypothesis is spatial randomness, that is, there is the absence of spatial dependence in the data. Intuitively, spatial randomness can be expressed as follows: values of an attribute at a location do not depend on values of an attribute at neighboring locations.

Figure 2 reports the global Moran's I statistics for all municipalities in Brazil in 2006. The statistical evidence casts doubt on the assumption of spatial randomness of the Lula performance in the elections. In fact, since the computed value of $I(0.7973)$ exceeds its theoretical value (zero), we can reject the hypothesis of no spatial autocorrelation at $0.1 \%$ significance level. ${ }^{3}$ These results are invariant with regards to convention of binary neighborhood used for the construction of the spatial weights (queen or rook). In

\footnotetext{
${ }^{3}$ Empirical pseudo-significance based on 999 random permutations.
} 
addition, Moran's I provides clear indication that the spatial autocorrelation for Lula's performance is positive. That is, municipalities with a high proportion of votes in the PT candidate are also adjacent to municipalities with a high proportion of Lula's voters. In an analogous manner, municipalities with a relative low preference for Lula are adjacent to municipalities with a low preference as well. That is the intuitive meaning of positive spatial autocorrelation.

An alternative approach to visualize spatial association is based on the concept of a Moran Scatterplot, which shows the spatial lag (i.e. the average of the attribute for the neighbors) on the vertical axis and the value at each location on the horizontal axis (see Figure 2). Note that the variables are expressed in standardized form with mean zero and standard deviation equal to one (Anselin, 1999, p. 261).

Figure 2. Moran Scatterplot and Global Moran's I Statistics for Lula's Performance in the First Round of the 2006 Presidential Elections

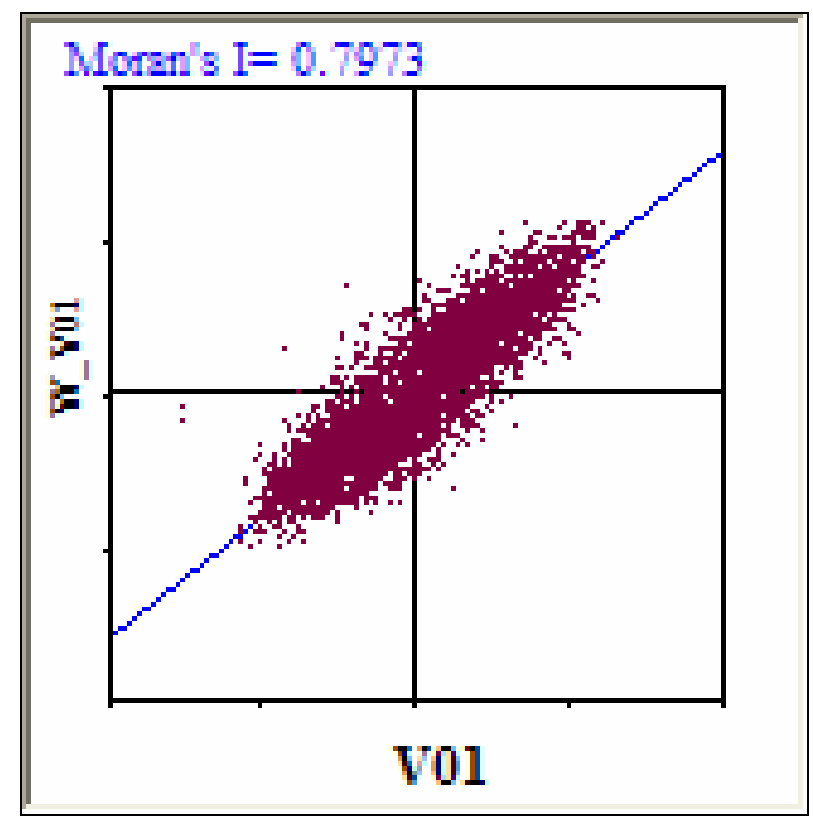

The global indicators of spatial association are not capable of identifying local patterns of spatial association, such as clusters or spatial outliers in the data that are statistically significant. To overcome this obstacle, it is necessary to implement a spatial clustering analysis. We used the local version of Moran's I (LISA statistics) as the basis for testing 
the null hypothesis of local randomness, that is, no local spatial association. Figure 3 combines the information of the Moran Scatterplot and the LISA statistics. It illustrates the classification into four categories of spatial association that are statistically significant in terms of the LISA concept. We find evidence of spatial grouping: overall, there are some clusters of municipalities where Lula obtained a better performance, located in the less developed regions of the North and Northeast, as well as neighbors with high percentage of votes for Lula. Likewise, there are clusters of low performance located in the Center-South of the country. The question is: does Lula's performance reflect his efforts in the first mandate to fight regional inequality or there is something else behind this seemingly paradoxal result, which shows that a government without any concrete regional policy action achieved its best evaluation in the regions that were left behind?

Figure 3. Moran Significance Map for Lula Voting

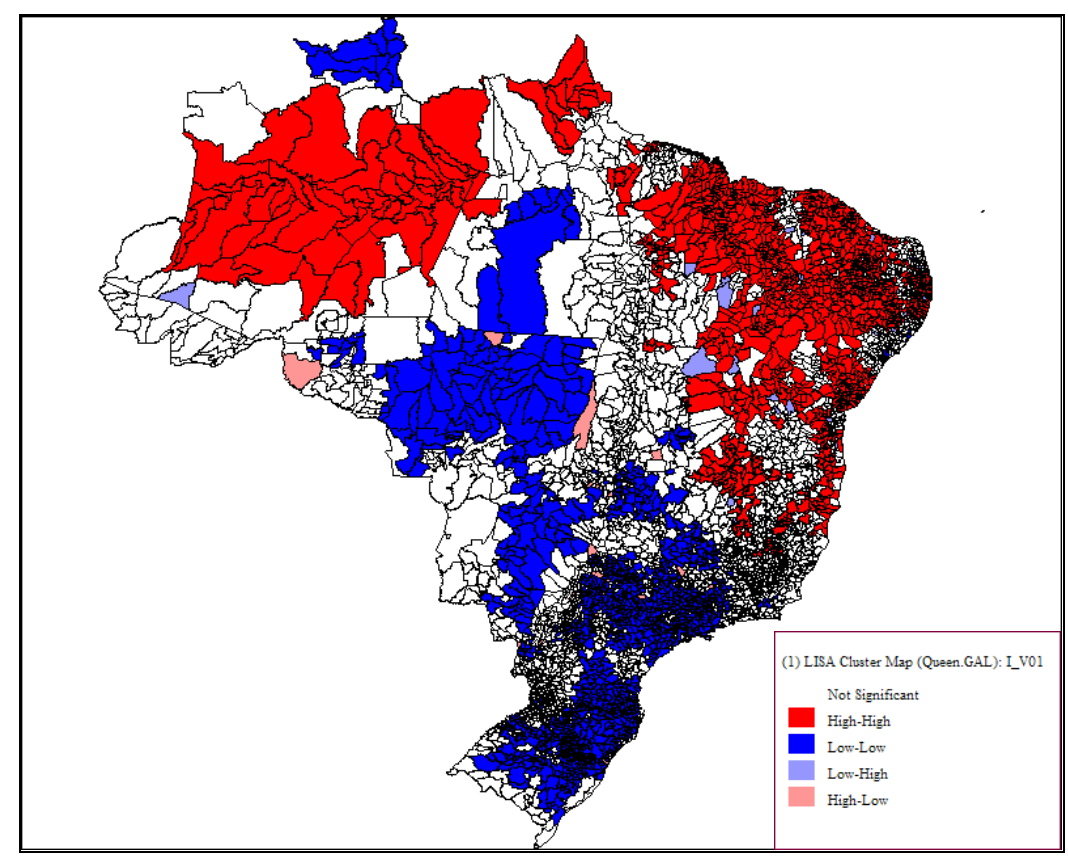

To tackle this issue, we estimated spatial econometric models to identify the main determinants of Lula's performance in the 2006 elections. The dependent variable is the percentage of Lula's voting in the first round of the presidential elections. We considered four groups of covariates in our models: 1. Spatial Structure Variables - Human 
Development Index, Gini Coefficient and Per Capita GDP, all for year 2000; 2. Structural Regional Policy Variables - Per Capita Constitutional Transfers and Per Capita Rural Pension Payments, both in 2006; 3. Social Policy Variables - Per Capita Income from Bolsa Família, 2006; Number of Households with Per Capita Income below R\$ 120,00 in 2000; 4. Economic and Political Variables - Dummy for Mayor affiliated to PSDB; Share of Agriculture in GDP, in 2002

The spatial structure variables attempt to capture the spatial distribution of economic development in the country, reflecting a long-standing situation of regional dualism, reflecting voters' perception according to different local socioeconomic profiles. The structural regional policy variables attempt to capture established regional policy, and therefore, a proper evaluation of the extra efforts by the central government. The set of social policy variables tries to capture not only an evaluation of the income transfer program, but also the expectation of its reinforcement in the second mandate. Finally, the economic and policy variables reflect the economic cycle and the local political scene affecting the evaluation of the current president.

Three models were estimated. The first model was estimated using OLS. The two other models introduced space in a formal way, as suggested by the diagnostics tests. We considered (i) the estimation by means of maximum likelihood of a spatial regression model that includes a spatially lagged dependent variable ${ }^{4}$, and (ii) the estimation by means of maximum likelihood of a spatial regression model that includes a spatial autoregressive error term ${ }^{5}$. Results are presented in Tables 2 and 3, below. Bold figures are statistically significant at $1 \%$ level.

In terms of the spatial structural variables, HDI and per capita GDP are negatively correlated with Lula's performance in the elections, while Gini coefficient is positively

\footnotetext{
${ }^{4}$ Formally, this model is $y=\rho W y+X \beta+\varepsilon$, where $y$ is a vector of observations on the dependent variable, $W y$ is a spatially lagged dependent variable for weights matrix $W, X$ is a matrix of observations on the explanatory variables, $\varepsilon$ is a vector of i.i.d. error terms, and $\rho$ and $\beta$ are parameters.

${ }^{5}$ Formally, this model is $y=X \beta+\varepsilon$, with $\varepsilon=\lambda W \varepsilon+u$, where $y$ is a vector of observations on the dependent variable, $W$ is the spatial weights matrix, $X$ is a matrix of observations on the explanatory variables, $\varepsilon$ is a vector of spatially autocorrelated error terms, $u$ a vector of i.i.d. errors, and $\beta$ and $\lambda$ are parameters.
} 
correlated. In other words, the more developed, the richer and the less unequal the municipality, the lower the percentage voting in Lula at that locality.

Moreover, in municipalities that are more benefited by structural regional policies, Lula presented a weaker performance in the first round of the elections. In our view, this reflects the neglecting of regional policy by the current government, as these regions, traditionally reliant on government compensatory regional policies, had their expectation frustrated by the almost null extra efforts set in this direction.

Noteworthy is the robustness of the social policy variables. Municipalities with higher per capita transfers through the "Bolsa Familia Program" and with the potential for its consolidation in the future, presented a positive evaluation of the Lula's first mandate translated into greater proportion of votes.

Regarding economic and political variables, current economic situation previous to elections, which hampered the agricultural sector (e.g. appreciation of Real, droughts, collapse of agricultural insurance funds), seem to have negatively affected Lula's performance in the rural areas. Finally, from a political perspective, the role played by mayors belonging to the main opposition party, the PSDB, also influenced negatively Lula's voting in those municipalities.

In this context, in the next sections we take a closer look at the "Bolsa Familia Program" from a regional perspective. We start by describing the Miyazawa framework, which will be used as the analytical tool for the evaluation of the Program. 
Table 2. Quantitative Estimation Results (Dependent Variable: \% of Lula's Voting)

\begin{tabular}{lccc}
\hline \multirow{2}{*}{ Coefficients } & \multicolumn{3}{c}{ Model } \\
\cline { 2 - 4 } & OLS & Spatial Lag & Spatial Error \\
\hline W_Lula & - & $\mathbf{0 . 7 4 2 2 0 6 6 0}$ & - \\
Constant & $\mathbf{0 . 7 3 3 4 9 1 2 0}$ & $\mathbf{0 . 1 6 5 4 7 2 1 0}$ & $\mathbf{0 . 5 7 5 4 3 6 3 0}$ \\
HDI & $\mathbf{- . 4 3 1 0 0 7 6 0}$ & -0.00628164 & $\mathbf{- 0 . 1 5 1 8 1 8 0 0}$ \\
Gini & $\mathbf{0 . 1 8 5 6 7 5 2 0}$ & -0.00186970 & $\mathbf{0 . 0 7 7 0 0 8 7 3}$ \\
GDP (per capita) & $\mathbf{- . 0 0 0 5 1 0 6 6}$ & $\mathbf{- 0 . 0 0 0 2 5 7 5 5}$ & $\mathbf{- 0 . 0 0 0 3 0 4 0 5}$ \\
Constitutional transfers (per capita) & $\mathbf{- 0 . 0 0 0 2 0 9 0 4}$ & $\mathbf{- 0 . 0 0 0 0 6 9 8 8}$ & $\mathbf{- 0 . 0 0 0 0 7 2 1 0}$ \\
Bolsa Familia income (per capita) & $\mathbf{0 . 0 0 0 6 7 0 5 3}$ & $\mathbf{0 . 0 0 0 2 2 4 5 1}$ & $\mathbf{0 . 0 0 0 2 2 8 9 3}$ \\
Rural pensions (per capita) & $\mathbf{- . 0 0 0 0 0 6 7 1}$ & $\mathbf{- 0 . 0 0 0 0 0 5 4 0}$ & $\mathbf{- 0 . 0 0 0 0 0 4 2 3}$ \\
Number of poor households & $\mathbf{0 . 0 0 0 0 0 1 5 3}$ & $\mathbf{0 . 0 0 0 0 0 0 2 7}$ & $\mathbf{0 . 0 0 0 0 0 0 0 1}$ \\
Dummy_PSDB & $\mathbf{- 0 . 0 1 4 3 4 2 5 4}$ & $\mathbf{- 0 . 0 0 6 5 9 8 0 0}$ & -0.00399306 \\
Share_Agriculture & $\mathbf{- . 0 5 9 6 5 7 1 4}$ & $\mathbf{- 0 . 0 1 3 8 9 7 3 2}$ & -0.00703614 \\
Lambda & - & - & $\mathbf{0 . 8 3 9 5 5 0 2 0}$ \\
R2 & & & \\
\hline
\end{tabular}

Table 3. Qualitative Estimation Results (Dependent Variable: \% Lula's Voting)

\begin{tabular}{lccc}
\hline \multirow{2}{*}{ Coefficients } & \multicolumn{3}{c}{ Model } \\
\cline { 2 - 4 } & OLS & Spatial Lag & Spatial Error \\
\hline W_Lula & - & $(+)$ & - \\
Constant & $(+)$ & $(+)$ & $(+)$ \\
HDI & $(-)$ & n.s. & $(-)$ \\
Gini & $(+)$ & n.s. & $(+)$ \\
GDP(per capita) & $(-)$ & $(-)$ & $(-)$ \\
Constitutional transfers (per capita) & $(-)$ & $(-)$ & $(-)$ \\
Bolsa Familia income (per capita) & $(+)$ & $(+)$ & $(+)$ \\
Rural pensions (per capita) & $(-)$ & $(-)$ & $(-)$ \\
Number of poor households & $(+)$ & $(+)$ & $(+)$ \\
Dummy_PSDB & $(-)$ & $(-)$ & n.s. \\
Share_Agriculture & $(-)$ & $(-)$ & n.s. \\
Lambda & - & - & $(+)$ \\
\hline
\end{tabular}




\section{Economic impacts: The Miyazawa Framework ${ }^{6}$}

In this paper we use a Leontief-Miazawa model, in which the intersectoral flows in the economy can be represented by a system of simultaneous equations such as $X=A X+Y$, in which $X$ is a $(n x 1)$ vector of sectoral production values, $Y$ is a $(n x 1)$ vector of sectoral final demands and $\mathrm{A}$ is $\mathrm{a}(n \times n)$ matrix of technical production coefficients. If final demand is treated as exogenous to the system, we have $X=B Y$ and $B=(I-A)^{-1}$, with $B$ being the $(n x n)$ Leontief inverse matrix. If the internal consumption demand is detached from the final demand vector, the model becomes $Y=Y^{c}+Y^{e}$, in which $Y^{c}$ is a (nx1) vector of income related consumption demand and $Y^{e}$ is the $(n x 1)$ vector of exogenous demand (government expenditure, investment, exports).

The multi sectoral consumption function is $Y^{c}=C \cdot Q$, in which $C$ is a $(n x r)$ matrix of consumption coefficients, and $Q$ is a $(r x 1)$ vector of total income for each income group. The elements of matrix $C$ are the quantity of product $i$ consumed by the $k^{\text {th }}$ income group. Income distribution is introduced by $Q=V . X$, in which $V$ is the $(r x n)$ matrix of shares of family's income on total production, by sector and income class. This last equation connects the productive structure to income distribution.

By manipulating the above expressions, one gets $X=(I-A-C \cdot V)^{-1} \cdot Y_{e}$. Considering that $B=(I-A)^{-1}$, one can write $X=B(I-C V B)^{-1} \cdot Y_{e}$. The extension of the model to a multi-regional setting demands the consideration of interregional flows of inputs and outputs. Let $Z_{i, j}^{R m, R n}$ be the monetary flow from sector $i$ in region $R_{m}$ to sector $j$ in region $R_{n}$. The chart below presents the interregional flows.

\footnotetext{
${ }^{6}$ The detailed model can be found in Moreira (2007)
} 


\begin{tabular}{|c|c|c|c|c|c|c|}
\hline & \multicolumn{5}{|c|}{ Sectors and Regions } \\
\hline & & $\begin{array}{c}\text { North }(\mathbf{N}) \\
(\mathbf{i} \ldots \mathbf{j}) \\
\end{array}$ & $\begin{array}{c}\text { Northwest } \\
\text { (NE) } \\
(\mathbf{i} \text {... j) } \\
\end{array}$ & $\begin{array}{c}\text { Mid-West } \\
(\mathbf{C O}) \\
(\mathbf{i} \text {... j }) \\
\end{array}$ & $\begin{array}{c}\text { Southeast (SE) } \\
(\mathbf{i} \text {... j) } \\
\end{array}$ & $\begin{array}{c}\text { South (S) } \\
(\mathbf{i} \text {... j) } \\
\end{array}$ \\
\hline \multirow{5}{*}{ 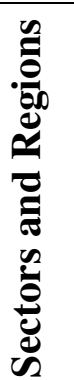 } & $\mathbf{N}(\mathbf{i} . . . j)$ & $\mathrm{Zij}(\mathrm{N} \times \mathrm{N})$ & Zij (N x NE) & $\mathrm{Zij}(\mathrm{N} x \mathrm{xCO})$ & Zij (N x SE) & $\mathrm{Zij}(\mathrm{N} x \mathrm{~S})$ \\
\hline & NE (i...j) & $\mathrm{Zij}(\mathrm{NE} \times \mathrm{N})$ & $\mathrm{Zij}(\mathrm{NE} \times \mathrm{NE})$ & $\mathrm{Zij}(\mathrm{NE} x \mathrm{xO})$ & Zij (NE x SE) & $\mathrm{Zij}(\mathrm{NE} \times \mathrm{S})$ \\
\hline & $\begin{array}{c}\mathrm{CO} \\
(\mathrm{i} . . . \mathrm{j})\end{array}$ & $\mathrm{Zij}(\mathrm{CO} \times \mathrm{N})$ & $\mathrm{Zij}(\mathrm{CO} \times \mathrm{NE})$ & $\mathrm{Zij}(\mathrm{CO} \times \mathrm{CO})$ & $\mathrm{Zij}(\mathrm{CO}$ x SE) & $\mathrm{Zij}(\mathrm{CO} \times \mathrm{S})$ \\
\hline & SE (i...j) & $\mathrm{Zij}(\mathrm{SE} \times \mathrm{N})$ & Zij (SE x NE) & Zij (SE xCO) & Zij (SE x SE) & $\mathrm{Zij}(\mathrm{SE} \times \mathrm{S})$ \\
\hline & $S(\mathbf{i} . . . j)$ & $\mathrm{Zij}(\mathrm{S} \times \mathrm{N})$ & Zij (S x NE) & Zij (S xCO) & $\mathrm{Zij}(\mathrm{S} \times \mathrm{SE})$ & Zij $(S \times S)$ \\
\hline
\end{tabular}

The five macro regions of Brazil were considered, and their economic structures were split into 21 sectors. Therefore, the model uses five 21 x 21 input-output tables, including interregional trade flows. Data referring to income distribution by sector and region comes from 2002 PNAD - Pesquisa Nacional Por Amostra de Domicílios, also produced by IBGE. Ten income brackets were considered (R $\$$ /month): from zero income to 400 (5.3\% of total national household income); $400-600$ (5.4\%); $600-1,000$ (11.5\%); 1,000 - 1,200 (5.3\%); 1,200 - 1,600 (8.9\%); 1,600 - 2,000 (8.3\%); 2,000 - 3,000 (13.7\%); $3,000-4,000(9.7 \%) ; 4,000-6,000(11.9 \%)$; and 6,000 and over (19.8\%). The household expenditure patterns for each income bracket in each region are taken into account. Consumption data comes from the 2002-2003 POF - Pesquisa de Orçamentos Familiares, implemented by IBGE.

\section{Simulation Results}

The interregional Leontief-Miazawa model briefly described in the previous section was estimated for 2002, the last year before the start of President Lula's first period of administration. The simulation strategy is to introduce a shock to that productive and distributional situation and to evaluate its impacts. The 2002 base case situation already included some influence of social programs, for they started during the previous administration. 
Therefore, the first step was to determine what were the amounts involved in each region. Table 4 presents the basic data. The columns referring to 2004, 2005 and 2006 present the effective amounts distributed by Bolsa Família. For 2002 and 2003 the data were not disaggregated spatially, so that some estimates had to be made. The 2003 PNAD presents a special segment on social programs, and the data could be used. A comparison of income received by low income persons in 2005 PNAD was made with the official Bolsa Família data and the approximation was reasonably good. Therefore, regional shares of the 2002 PNAD data on the distribution of "interests, profits, dividends and others" to very low-income persons was considered to be the benchmark for the simulations.

As the table indicates, the average annual expenditure on the program more than doubled during the Lula administration. For the country as a whole there was a $151 \%$ increase, but for the poor Northeast region the increase was of $351 \%$. For the richer Southeast region, the increase was of only $92 \%$. This gives a first information on the regional impacts of such programs. However, in order to assess their final impact, these changes in expenditure have to be introduced in the model presented in the previous section. We have shocked the earnings of the poorest income bracket in each region by the increase in government transfers to that region. We did it in two steps: initially, this extra money was introduced in the region as an absolute increase in government expenditure. In the second step we considered that this extra money had to come from reduced government current expenditures. Since the chain of interrelations in the system is different from the two forms of expenditure, it is expected that the final results on income distribution will also be different. 
Table 4 - Government transfers to families by region - Bolsa Família (*)

\begin{tabular}{|c|c|c|c|c|c|c|}
\hline & $\begin{array}{c}2002 \\
(1)\end{array}$ & $\begin{array}{c}2003 \\
(2)\end{array}$ & 2004 & 2005 & 2006 & $\begin{array}{c}\text { Lula's } \\
\text { Administration }\end{array}$ \\
\hline \multicolumn{7}{|c|}{$R \$ 1,000$ of 2002} \\
\hline Mid-West & 130.797 & 219.383 & 226.801 & 300.167 & 376.739 & 1.123 .090 \\
\hline North & 119.168 & 242.595 & 482.206 & 618.950 & 805.087 & 2.148 .839 \\
\hline Northeast & 1.169 .922 & 1.676 .519 & 3.111 .165 & 3.623 .624 & 4.281 .900 & 12.693 .208 \\
\hline South & 231.267 & 414.757 & 525.039 & 692.920 & 750.044 & 2.382 .759 \\
\hline Southeast & 756.846 & 891.746 & 1.247 .910 & 1.720 .518 & 1.964 .509 & 5.824 .682 \\
\hline Total & 2.408 .000 & 3.445 .000 & 5.593 .121 & 6.956 .179 & 8.178 .279 & 24.172 .579 \\
\hline \multicolumn{7}{|c|}{ Regional shares } \\
\hline Mid-West & $5,4 \%$ & $6,4 \%$ & $4,1 \%$ & $4,3 \%$ & $4,6 \%$ & $4,6 \%$ \\
\hline North & $4,9 \%$ & $7,0 \%$ & $8,6 \%$ & $8,9 \%$ & $9,8 \%$ & $8,9 \%$ \\
\hline Northeast & $48,6 \%$ & $48,7 \%$ & $55,6 \%$ & $52,1 \%$ & $52,4 \%$ & $52,5 \%$ \\
\hline South & $9,6 \%$ & $12,0 \%$ & $9,4 \%$ & $10,0 \%$ & $9,2 \%$ & $9,9 \%$ \\
\hline Southeast & $31,4 \%$ & $25,9 \%$ & $22,3 \%$ & $24,7 \%$ & $24,0 \%$ & $24,1 \%$ \\
\hline Total & $100,0 \%$ & $100,0 \%$ & $100,0 \%$ & $100,0 \%$ & $100,0 \%$ & $100,0 \%$ \\
\hline
\end{tabular}

(1) Based on "interests, profits, dividends and others" received by individuals with total earnings below R\$120 in the Norttheast, $\mathrm{R} \$ 130$ in the North, and $\mathrm{R} \$ 140$ in the other three regions

(2) PNAD 2003, special segment on social programs

(*) Untill 2003 payments to auxílio-gás, bolsa alimentação, bolsa escola and cartão alimentação were summed.

These separate programs were unified in 2004 under the Bolsa-Família program. Official data from 2004 on.

The size of the shock simulated is of $\mathrm{R} \$ 24.172$ billion, encompassing the four years of the administration. On a yearly basis, it represents $0.45 \%$ of national GDP, $0.82 \%$ of national disposable income, and $13.4 \%$ for the poorest income bracket. The results presented on Table 5 indicate that this expenditure increases national GDP by $2.96 \%$, averaging $0.74 \%$ per year. Since more money was given to poor families, the largest impacts occurred in the production of manufactured food, agriculture, rent, transportation, public utilities, textiles, chemicals and plastics, and communication. In regional terms, the Northeast region is the most affected, with a GDP increase of 7.2\% (1.8\% per year, on average), 2.4 times the national increase. The North region is second, with 3.35\% increase in GDP, and the Mid-West and Southeast regions are the least affected, with GDP increases of $2.1 \%$. 
Considering the distributive aspects, the largest disposable income increase is presented by the poorest income bracket, as expected, with a national $2.7 \%$ increase, but $8.6 \%$ in the Northeast. The national average (all income brackets) presents an increase of $2.2 \%$, smaller than the increase in GDP. The national Gini moves from 0.5280 in 2002 to 0.5266 after the shocks, a decrease of $0.25 \%$. This shows that the annual impact of the Bolsa Família program is limited, although positive (Table 6).

The above simulation assumes an unrealistic situation in which government increases its current expenditure to take care of the social program. The next simulation considers that government total expenditure is constant, and that the extra payment to families is subtracted from other current expenditures. For that, the previous distribution of government current expenditure was used to distribute the amount compensated among sectors and regions.

As expected, now the impact on national GDP is different, as Table 5 shows (the 5 largest impacts are highlighted). As a matter of fact, it becomes negative, $-0.48 \%$, and average of $-0.12 \%$ per year. This happens because the multiplier effects of the sectors negatively affected are larger than the positively affected sectors. The same sectors most affected in the previous simulation are affected now, with lower impacts. But now some sectors are negatively affected, such as public administration, services to business, services to families, non mercantile services, communication, other manufacturing, vehicles, commerce, financial services, wood and furniture and even construction. The largest positive impacts accrue to manufactured food, agriculture, transportation and textiles, but rents, chemicals and plastic, mining, machinery and equipment, public utilizes and metals also receive some positive effects. 
Table 5 - Impacts on production, by sector and region

Impacts on production

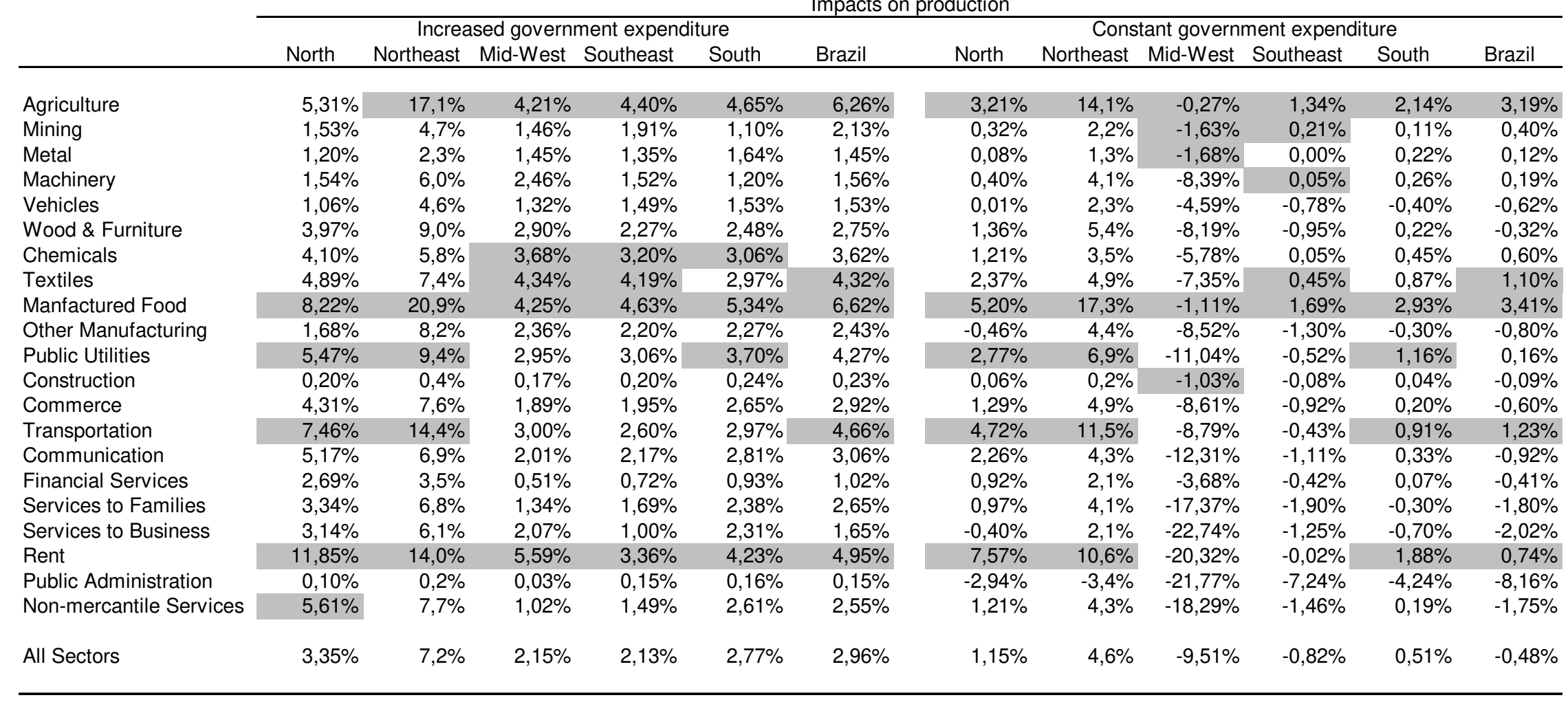


Table 6 - Impacts on household income by region

Impacts on household income

\begin{tabular}{|c|c|c|c|c|c|c|c|c|c|c|c|c|c|}
\hline \multirow{3}{*}{ Income brackets } & \multirow{3}{*}{$\begin{array}{l}\text { Share } \\
2002)\end{array}$} & \\
\hline & & \multicolumn{6}{|c|}{ Increased government expenditure } & \multicolumn{6}{|c|}{ Constant government expenditure } \\
\hline & & North & Northeast & Mid-West & Southeast & South & Brazil & North & Northeast & Mid-West & Southeast & South & Brazil \\
\hline Up to $400(1)$ & $5,3 \%$ & $3,27 \%$ & $8,6 \%$ & $1,51 \%$ & $2,11 \%$ & $2,63 \%$ & $4,93 \%$ & $1,02 \%$ & $6,0 \%$ & $-12,77 \%$ & $-0,97 \%$ & $0,37 \%$ & $1,72 \%$ \\
\hline $400-600$ & $5,4 \%$ & $2,87 \%$ & $7,6 \%$ & $1,44 \%$ & $1,93 \%$ & $2,50 \%$ & $3,67 \%$ & $0,69 \%$ & $4,9 \%$ & $-13,13 \%$ & $-1,13 \%$ & $0,21 \%$ & $0,33 \%$ \\
\hline 600 to 1,000 & $11,5 \%$ & $2,77 \%$ & $6,4 \%$ & $1,24 \%$ & $1,82 \%$ & $2,34 \%$ & $2,85 \%$ & $0,45 \%$ & $3,6 \%$ & $-14,61 \%$ & $-1,48 \%$ & $-0,07 \%$ & $-0,77 \%$ \\
\hline 1,000 to 1,200 & $5,3 \%$ & $2,30 \%$ & $5,4 \%$ & $1,10 \%$ & $1,62 \%$ & $2,18 \%$ & $2,31 \%$ & $-0,17 \%$ & $2,5 \%$ & $-15,50 \%$ & $-2,05 \%$ & $-0,28 \%$ & $-1,60 \%$ \\
\hline 1,200 to 1,600 & $8,9 \%$ & $2,38 \%$ & $5,6 \%$ & $0,85 \%$ & $1,59 \%$ & $2,13 \%$ & $2,27 \%$ & $-0,13 \%$ & $2,8 \%$ & $-16,52 \%$ & $-2,13 \%$ & $-0,46 \%$ & $-1,86 \%$ \\
\hline 1,600 to 2,000 & $8,3 \%$ & $2,55 \%$ & $5,3 \%$ & $0,81 \%$ & $1,50 \%$ & $2,01 \%$ & $2,07 \%$ & $-0,01 \%$ & $2,4 \%$ & $-16,77 \%$ & $-2,31 \%$ & $-0,57 \%$ & $-2,13 \%$ \\
\hline 2,000 to 3,000 & $13,7 \%$ & $2,29 \%$ & $5,4 \%$ & $0,73 \%$ & $1,42 \%$ & $1,97 \%$ & $2,00 \%$ & $-0,30 \%$ & $2,5 \%$ & $-17,26 \%$ & $-2,50 \%$ & $-0,73 \%$ & $-2,54 \%$ \\
\hline 3,000 to 4,000 & $9,7 \%$ & $2,39 \%$ & $5,9 \%$ & $0,61 \%$ & $1,48 \%$ & $1,91 \%$ & $2,08 \%$ & $-0,28 \%$ & $3,0 \%$ & $-17,32 \%$ & $-2,43 \%$ & $-0,75 \%$ & $-2,62 \%$ \\
\hline 4,000 to 6,000 & $11,9 \%$ & $2,21 \%$ & $5,0 \%$ & $0,59 \%$ & $1,47 \%$ & $2,00 \%$ & $1,96 \%$ & $-0,36 \%$ & $2,1 \%$ & $-17,17 \%$ & $-2,25 \%$ & $-0,60 \%$ & $-2,58 \%$ \\
\hline more & $19,8 \%$ & $2,92 \%$ & $4,6 \%$ & $0,61 \%$ & $1,56 \%$ & $2,28 \%$ & $2,03 \%$ & $0,18 \%$ & $1,7 \%$ & $-17,38 \%$ & $-1,90 \%$ & $-0,35 \%$ & $-2,76 \%$ \\
\hline All brackets & & $2,64 \%$ & $6,1 \%$ & $0,80 \%$ & $1,59 \%$ & $2,16 \%$ & $2,45 \%$ & $0,15 \%$ & $3,3 \%$ & $-16,55 \%$ & $-2,01 \%$ & $-0,39 \%$ & $-1,78 \%$ \\
\hline
\end{tabular}

(1) Includes zero income 
Now the GDP in the Northeast grows only 4.6\%, an average of $1.1 \%$ per year. At a lower level, the North and South regions also get some positive effects. Negative impacts are present in the Southeast $(-0.82 \%)$ and, mainly, in the Mid-West $(-9.5 \%)$. This is explained by the important presence of the federal government in Brasília. As for income classes (Table 6), only the two poorest brackets increase their values, with all other receiving less money after the shock. An average Brazilian looses $1.78 \%$, an yearly average of $0.4 \%$. The very poor income bracket increases its earnings by $1.72 \%$ (yearly average of $0.42 \%$ ), and the second poorest by $0.33 \%$. The upper income bracket presents an income decrease of $2.76 \%$. This lose-gain situation is present in all regions but the Northeast, where even the richest receive income increases (1.72\% for the 4-year impact).

These changes lead to a larger change in the national Gini, which decreases $0.39 \%$ for the 4-year impact, moving from 0.5280 in 2002 to 0.5259 after the shock (Table 7). This indicates that the loosing sectors present a less pro-poor profile than the sectors that benefited from the social programs. Table 5 allows for a comparison of the two shocks simulated here. The Mid-West region presents the highest inequality 2002, probably due to the presence of the Federal District, which is known for having the highest per capita income in the country. The poor Northeast region comes second, with the South being the least unequal. The first shock, which assumes increase in total government expenditure in the amount of the Bolsa Família payments, indicates that the Northeast region will present the most improvement in income inequality, a $0.51 \%$ decrease in its Gini indicator; the second best would be the Southeast, with $-0.08 \%$. Considering that government has to compensate the extra expenditure with cuts in other programs changes the scenario. As mentioned before, the global improvement in income distribution is larger. The Northeast region is still the most benefited, even more than in the previous case, but the highlight is the Mid-West region, with the largest change in the Gini coefficient, $-0.67 \%$. In spite of this, the region maintain its first place in inequality levels. 
Table 7 - Impacts on income inequality

\begin{tabular}{lcrrrr}
\hline & Observed & \multicolumn{3}{c}{ After Shock } \\
\cline { 3 - 6 } & 2002 & \multicolumn{2}{c}{$\begin{array}{c}\text { Increased } \\
\text { government } \\
\end{array}$} & Gini & \multicolumn{2}{c}{$\begin{array}{c}\text { Constant } \\
\text { government } \\
\text { Gini }\end{array}$} & Change & Gini & Changenditure \\
\hline North & 0,4659 & 0,4661 & $0,04 \%$ & 0,4655 & $-0,07 \%$ \\
Northeast & 0,4988 & 0,4962 & $-0,51 \%$ & 0,4961 & $-0,54 \%$ \\
Mid-West & 0,5353 & 0,5351 & $-0,05 \%$ & 0,5317 & $-0,67 \%$ \\
Southeast & 0,4666 & 0,4662 & $-0,08 \%$ & 0,4661 & $-0,10 \%$ \\
South & 0,4580 & 0,4579 & $-0,02 \%$ & 0,4576 & $-0,10 \%$ \\
Brazil & 0,5280 & 0,5266 & $-0,26 \%$ & 0,5259 & $-0,39 \%$ \\
\hline
\end{tabular}

As for regional concentration, the main object of this paper, the effects are clearly favorable as Table 8 indicates. The Northeast region increases its share in national GDP from $12.9 \%$ to $13.56 \%$ and in national income from $16.9 \%$ to $17.78 \%$; the North region moves from $4,76 \%$ to $4,83 \%$ in GDP and from $5 \%$ to $5.1 \%$ in terms of income. The Southeast region loses share, from $56.11 \%$ to $55.92 \%$ in GDP, and from $54.45 \%$ to $54.32 \%$ in terms of income. The Mid-West region presents the largest loss, from 7.98 to 7.26 in GDP, and from $7.24 \%$ to $6.16 \%$ in income. The South region increases its shares, from $18.25 \%$ to $18.44 \%$ in GDP, and from $16.41 \%$ to $16.64 \%$ in income.

Thus, clearly the Bolsa Família program presents a clear favorable regional impact. Since it is target to poor families, and those are mainly located in poorer regions, it ends-up producing a deconcentration effect. This effect is larger if government expenditure is held fixed, since the regional pattern of the global effects of government expenditure is proconcentration than the global effects of the expenditure of poor families.

\section{Final Remarks}

This paper has shown that the Bolsa Família program produces positive impacts on income concentration, both at the individual level and at the regional level. Assuming that it could be continued forever, it could end up producing important improvements in income inequality in the country. However, the long term effects of such programs, vis-à- 
vis other types of social intervention (education, health) should be taken into consideration. If expanded government investments in social transfers hurt other investment-related programs, it will clearly produce a set back in the future.

Table 8. Shares in production value and in income

\begin{tabular}{lccc}
\cline { 2 - 4 } & Base line 2002 & $\begin{array}{c}\text { Without expenditure } \\
\text { compensation }\end{array}$ & $\begin{array}{c}\text { Holding government } \\
\text { expenditure constant }\end{array}$ \\
\cline { 2 - 4 } & \multicolumn{3}{c}{ Shares in GDP } \\
North & $4,76 \%$ & $4,77 \%$ & $4,83 \%$ \\
Northeast & $12,90 \%$ & $13,43 \%$ & $13,56 \%$ \\
Mid-West & $7,98 \%$ & $7,92 \%$ & $7,26 \%$ \\
Southeast & $56,11 \%$ & $55,66 \%$ & $55,92 \%$ \\
South & $18,25 \%$ & $18,22 \%$ & $18,44 \%$ \\
& & Shares in disposable income & \\
& & & \\
North & $5,00 \%$ & $5,01 \%$ & $17,78 \%$ \\
Northeast & $16,90 \%$ & $17,51 \%$ & $6,16 \%$ \\
Mid-West & $7,24 \%$ & $7,13 \%$ & $54,32 \%$ \\
Southeast & $54,45 \%$ & $53,99 \%$ & $16,64 \%$ \\
South & $16,41 \%$ & $16,36 \%$ & \\
\hline
\end{tabular}

Much more is needed to foster development in the lagging regions: structural policies looking at both (i) the supply (human capital) and (ii) the demand side (physical capital). Recent government initiatives in Brazil to promote investments in infrastructure include the Programa de Aceleração do Crescimento (PAC, growth acceleration program), unveiled at the end of January 2007. ${ }^{7}$ Investments in logistic infrastructure are estimated in USD 58.3 billions in the four-year period 2007-2010, USD 33.4 billions $(57.3 \%$ of the total) only in road infrastructure. ${ }^{8}$

One important aspect of macroeconomic management in Brazil, with potential effects on the public provision of infrastructure, is the Projeto Piloto de Investimento (PPI, pilot

\footnotetext{
${ }^{7}$ The PAC will aim to raise average annual GDP growth to 5\% per year (almost double the country's longterm average), principally through increased investment in infrastructure, which will be fostered in part through targeted tax breaks (EIU, February 2007).

${ }^{8}$ www.brasil.gov.br (Programa de Aceleração do Crescimento 2007-2010).
} 
project for investment), which permits the government to reduce the primary surplus by an equivalent amount to an increase in infrastructure expenditure. PPI will probably be increased from $0.2 \%$ of GDP to $0.5 \%$ of GDP. As the government has formally maintained the $4.25 \%$ of GDP primary fiscal target ${ }^{9}$ in 2007 , this will put the effective primary surplus closer to $3.75 \%$ of GDP. ${ }^{10}$ In monetary terms, this may represent additional USD 1.9 to 4.7 billions to be invested in infrastructure, according to Fipe estimates for the PNLT.

Concomitantly to the four-year program (PAC), the central government has also signaled its intention in reviving long term planning in transportation in the country. The design of an ambitious "Plano Nacional de Logística e Transportes" (PNLT, national plan of logistics and transportation) has been initiated, involving different stakeholders. It aims at supporting decision makers in attaining economic objectives through policy initiatives related to both public and private infrastructure and organization of the transportation sector. ${ }^{11}$

Helping the poor is a valid objective. In the short run, the Bolsa Família program has proven to produce positive results, both at the personal income level and at the regional concentration level, and has surely paid large dividends in electoral terms. Solving inequality problems, however, might need other mid and long run policies which could improve competitiveness of lagging regions.

\section{References}

Albuquerque, R. C. and Gomes, R. M. (1996). Nordeste: Os Desafios de uma Dupla Inserção. In Fórum Nacional: O Real, o Crescimento e as Reformas, Ed. J. P. R. Velloso, José Olympio Editora, Rio de Janeiro.

Amann, E., Haddad, E. A., Perobelli, F. and Guilhoto, J. (2006). Structural Change in the Brazilian Automotive Industry and Its Regional Impacts. Latin American Business Review, vol. 7, n. 3-4.

\footnotetext{
${ }^{9}$ Primary non-financial public-sector (NFPS) balance (excluding interest payments).

${ }^{10}$ EIU (2007).

${ }^{11}$ www.centran.eb.br (Programa Nacional de Logística e Transportes).
} 
Anselin, L. (1999). Interactive Techniques and Exploratory Spatial Data Analysis. In Geographic Information System: Principles, Techniques, Manegement and Applications, edited by P. A. Longley, M.F. Goodchild, D. J. Maguire and D. W. Rhind. New York: John Wiley, pp. 251-264.

Araújo, T. B. (1995). Nordeste, Nordestes: Que Nordeste? In Federalismo no Brasil: Desigualdae Regionais e Desenvolvimento, Eds. R. B. A. Affonso and P. L. B. Silva, FUNDAP, São Paulo.

Goldberg, S. (1958). Introduction to Difference Equations. New York: Wiley.

Haddad, E. A. (1999). Regional Inequality and Structural Changes: Lessons from the Brazilian Experience. Ashgate, Aldershot.

Kalecki, M. (1968). Theory of Economic Dynamics. New York: Monthly Review Press.

Kalecki, M. (1971). Selected Essays on the Dynamics of the Capitalist Economy. Cambridge: Cambridge University Press.

Keynes, J. M. (1936). The General Theory of Employment, Interest, and Money. New York: Harcourt. 1964.

Leontief, W. W. (1951). The Structure of the American Economy. Second Enlarged Edition. New York: Oxford University Press.

Miyazawa, K. (1960). "Foreign Trade Multiplier, Input-Output Analysis and the Consumption Function." Quaterly Journal of Economics, Feb., vol. 74, no. 1.

Miyazawa, K. (1963). "Interindustry Analysis and the Structure of Income Distribution." Metroeconomica, Aug.-Dec., vol. 15, nos. 2-3.

Miyazawa, K. (1976). Input-Output Analysis and the Structure of Income Distribution. Berlin: Springer-Verlag.

Moreira, G. (2007) Políticas Sociais, Desigualdades Pessoais e Regionais da Renda no Brasil: Uma Análise de Insumo-Produto, Master Thesis, ESALQ-USP

Strang, G. (1980). Linear Algebra and Its Applications. 2nd. ed.. New York: Academic Press.

Temple, M. (1994). Regional Economics. New York: St. Martin’s Press 